\title{
Surveying the Upper Ocean with the Ocean Surveyor: A New Phased Array Doppler Current Profiler
}

\author{
Jürgen Fischer, Peter Brandt, Marcus Dengler, And Mario Müller \\ Institut für Meereskunde an der Universität Kiel, Kiel, Germany \\ DARRYL SYMONDS \\ RD Instruments, San Diego, California
}

(Manuscript received 10 December 2001, in final form 7 August 2002)

\begin{abstract}
A new shipboard current profiler, a 75-kHz ocean surveyor, was operationally used during two research cruises in the tropical Atlantic and the subpolar North Atlantic, respectively. Here, a report is presented on the first experience with this instrument in two very different current regimes, in the Tropics with large vertical shears, and in the subpolar regime with mainly barotropic flow. The ocean surveyor continuously measured currents in the upper ocean from near the surface to about 500-700-m depth. The measurement range showed a dependence on the regional and temporal variations of scattering particles and on the intensity of swell and wind waves. Statistical comparisons are performed with on-station lowered acoustic Doppler current profiler (LADCP) profiles and underway measurements by classic shipboard acoustic Doppler current profiler (ADCP) measurements. Accuracy estimates for hourly averaged ocean surveyor currents result in errors of about $1 \mathrm{~cm} \mathrm{~s}^{-1}$ for on-station data and of 2-4 $\mathrm{cm} \mathrm{s}^{-1}$ for underway measurements, depending on the regional abundance of scatterers and on the weather conditions encountered.
\end{abstract}

\section{Introduction}

Acoustic Doppler current profilers (ADCPs) have been used for almost 20 years in open ocean oceanographic research. These instruments are used in a variety of applications: for example, as shipboard devices for measuring the near-surface flow while the ship is under way (e.g., Joyce et al. 1982; Fischer et al. 1996); as moored instruments for remotely measuring intense surface currents and even vertical currents in convective regions (Schott et al. 1993, 1996); and as a device to measure full ocean depth current profiles on stations (Fischer and Visbeck 1993). A brief description of the history of ADCPs with focus on shipboard applications is found in King et al. (2001). The scientific community contributed much to the overall performance of shipboard ADCPs mainly by a continuous development of postprocessing algorithms (e.g., Joyce et al. 1982; Firing et al. 1989). However, most of the progress came from improvements in navigation data, which are needed to convert relative ADCP velocities into absolute currents. The introduction of the global positioning system (GPS) and GPS-based headings led to significant error reduc-

Corresponding author address: Dr. Jürgen Fischer, Institut für Meereskunde, Düsternbrooker Weg 20, Kiel 24105, Germany. E-mail: jifscher@ifm.uni-kiel.de tion in upper ocean currents measured by ADCPs. Since the beginning of the World Ocean Circulation Experiment (WOCE) Hydrographic Program (WHP) in 1990 most of the larger research vessels have been equipped with such an instrument.

The ocean surveyor (OS) is a new member of the family of shipboard acoustic current profilers used for underway measurements of upper ocean currents. RD Instruments (RDI) has been producing ADCPs since 1982 , and the narrowband (NB) $150-\mathrm{kHz}$ profiler has been the standard vessel-mounted ADCP since 1984. In 1992 the broadband (BB) ADCP was introduced by RDI to allow for higher vertical resolution and lower standard deviations than the NB-ADCP. However, the smaller range of a BB-ADCP of the same frequency and its sensitivity to rough sea conditions made this instrument ill-suited for open ocean research. This led to the development of the OS-ADCP, which offers the ability to perform the same processing capabilities as the NB- or BB-ADCP systems.

Here we report on the early use of such an instrument during a research cruise with R/V Sonne in the western tropical Atlantic (Fig. 1), and on the experience with the OS during two recent R/V Meteor cruises in the subpolar North Atlantic (Fig. 2). For comparison onstation simultaneous lowered ADCP (LADCP) measurements are available, and during the Meteor cruises a conventional $150-\mathrm{kHz}$ NB-ADCP was used in parallel. 
Tropical Atlantic

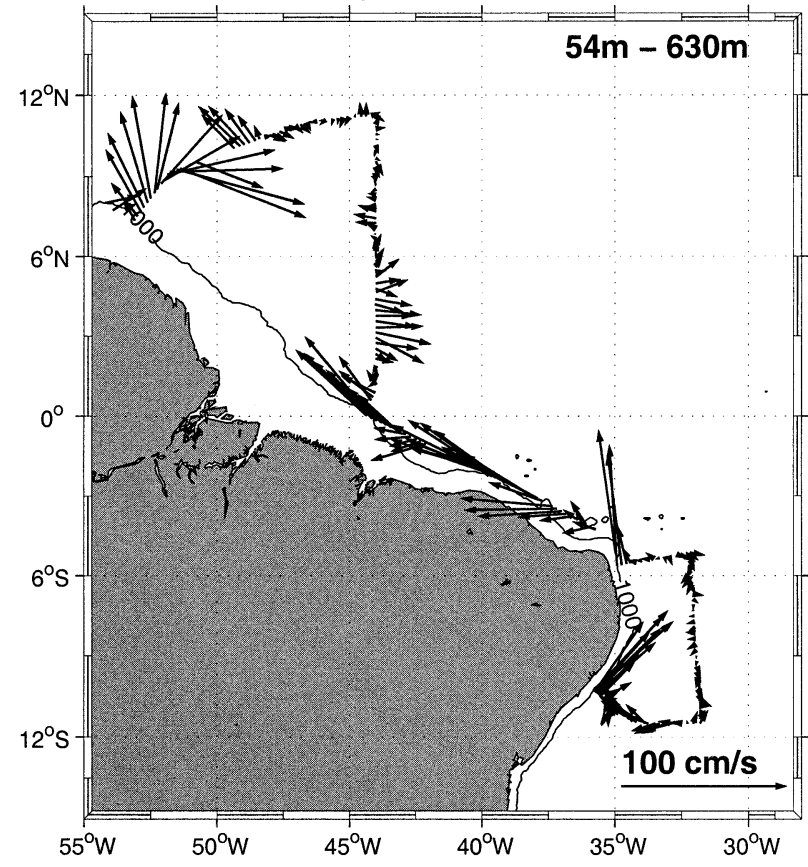

FIG. 1. Cruise track and upper-layer flow during the R/V Sonne cruise SO151. Current vectors are from the OS.

The two cruises were a good opportunity for testing the OS in different environmental conditions: a pretty calm sea state and high vertical shears in the Tropics, and partially very rough weather and mainly barotropic flow in the subpolar regions. It should be noted further that the horizontal scales of the flow field are much smaller in the subpolar region than in the Tropics. Due to time constraints, the above-mentioned cruises focused on the scientific work, not much time was allocated to instrument testing, and the OS setup was chosen as a compromise for range and vertical resolution. The focus of this paper is to show that the OS is suitable for operational use in blue water oceanography under a wide range of oceanic and meteorological situations.

\section{Technical details}

\section{a. The ocean surveyor specifications}

The OS-ADCP uses a phased array transducer. The phased array is a single flat-faced array of 36 times 36 elements that provides a more streamlined appearance than previous ADCP designs and results in less turbulence as water passes along it. The transducer head is comparably small, and a $75-\mathrm{kHz}$ transducer would fit into the same space that an NB- or BB-ADCP transducer of $150 \mathrm{kHz}$ would have required.

A signal processing deck unit is the second main part of the OS system and is controlled by the VMDAS software package that has to be installed on a quite powerful PC under WINDOWS control.
Subpolar North Atlantic

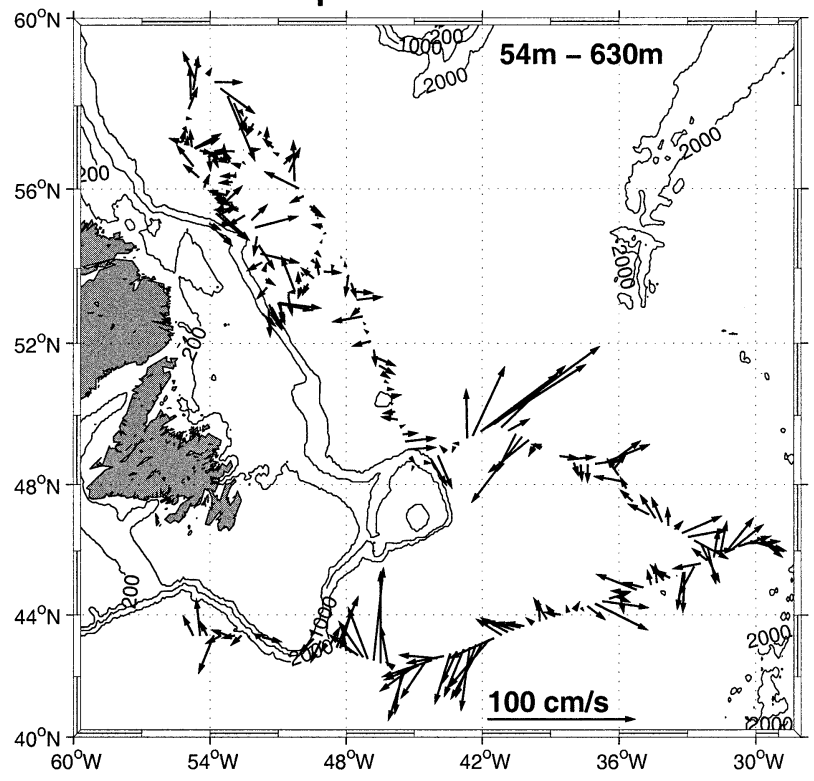

FIG. 2. Cruise track and upper-layer flow during the R/V Meteor cruises M50/1 and M50/2. Current vectors are from the OS.

The RDI phased array transducer is the only phased array transducer that simultaneously produces all four beams and sends off the acoustic pulses at the same time (i.e., not in a staggered sequence or delayed beam-bybeam transmission). As in the previous ADCP designs the four created beams are orientated in the Janus configuration, where four transducer beams are arranged $90^{\circ}$ apart. With respect to vertical the beams are inclined at angles of $30^{\circ}$.

Two modes of operation are possible, narrow bandwidth and broad bandwidth processing. The narrow bandwidth processing is implemented as it was done in the original NB-ADCP with an improvement to reduce skew biases. The narrow bandwidth processing uses low-pass filters to measure the returned Doppler energy spectrum. The intention is to center the filter position over the returned Doppler spectrum. If the filter is not positioned properly over the returned Doppler spectrum, then a skew error will occur. RDI's original NB-ADCP, which only uses narrow bandwidth processing, could obtain skew errors during large velocity changes from ping to ping (which are common when measuring from a vessel during rough weather) or when the shear in the water column is large (on the order of $2 \mathrm{~cm} \mathrm{~s}^{-1} \mathrm{~m}^{-1}$ ). The OS-ADCP narrow bandwidth processing implementation uses an iterative process that reduces skew errors by more than an order of magnitude compared to the original NB-ADCP. This is the mode we used during the Sonne and Meteor cruises, thus focusing on the larger range that could be achieved by this mode. In the NB mode, compared with the BB mode, the possibility of interference from other acoustic devices is 
TABLE 1. Nominal OS accuracies.

\begin{tabular}{lccc}
\hline \hline \multicolumn{1}{c}{ Mode } & $\begin{array}{c}\text { Cell size } \\
(\mathrm{m})\end{array}$ & $\begin{array}{c}\text { Range } \\
(\mathrm{m})\end{array}$ & $\begin{array}{c}\text { Single-ping } \\
\text { accuracy } \\
\left(\mathrm{cm} \mathrm{s}^{-1}\right)\end{array}$ \\
\hline Long range (NB) & 8 & $520-650$ & 30 \\
Long range (NB) & 16 & $560-700$ & 17 \\
High resolution (BB) & 8 & $310-430$ & 12 \\
High resolution (BB) & 16 & $350-450$ & 9 \\
\hline
\end{tabular}

reduced, which may be an important factor when using another ADCP in parallel.

The broad bandwidth processing is implemented as it was done in both the BB-ADCP and the WorkHorse (WH) ADCP with the exception that the bandwidth is approximately half of that used by default in either the BB- or WH-ADCP. However, the range in this broadband mode will be greater than the equivalent setup in either the BB- or WH-ADCP system of the same frequency, and the ping-to-ping accuracy is more than a factor of 2 better than with the narrow bandwidth processing.

A summary of the nominal OS accuracies for a 75$\mathrm{kHz}$ system is shown in Table 1, and from this it is immediately clear which mode would be appropriate for open ocean (deep water) applications. The high-resolution (or BB) mode shows sufficiently less range than the long-range (NB) mode. In this instrument the length of the depth cells coincides with the length of the acoustic pulses that are sent. Longer pulses transfer more energy into the water and therefore lead to increased depth ranges. In order to get as much range as possible and maintain a reasonable resolution of the near-surface currents, we used the long-range mode at 16-m depth cells.

\section{b. The $O S$ on board $R / V$ Sonne and $R / V$ Meteor}

The R/V Sonne cruise (SO151) was carried out during November 2000 in the western tropical Atlantic. The $\mathrm{R} / \mathrm{V}$ Sonne has two sea chests located about midship and very close together. In one of the two the OS was mounted with the transducer head at the level of the ship's hull. The ship's heading is needed to transform the measured flow, which is the flow relative to the transducer, into earth coordinates, and was provided as an analog gyro signal. Navigation data (positions) were from a differential GPS system. Additionally, digital heading was supplied by an Ashtech 3D GPS receiver. Usually, the R/V Sonne sailed at 12-13 kt during transit and was drifting between 0 and $2 \mathrm{kt}$ on conductivitytemperature-depth (CTD) stations, depending on wind and current speeds.

The R/V Meteor cruises M50/1 and M50/2 were carried out in the western subpolar North Atlantic during late spring 2001, experiencing more variable weather conditions ranging from calm days to severe storms. On the Meteor the OS setup was similar to that of the Sonne cruises, with the transducer head mounted midship in the ship's sea chest, and a $150-\mathrm{kHz}$ NB-ADCP in the bow part of the ship (built into the ship's hull).

Three different heading sources were available for the R/V Meteor cruises: a conventional gyro, a digital fiber optic gyro (FOG), and an Ashtech 3D-GPS receiver. While the FOG headings appear preferable to gyro headings, as there are no Schuler oscillations in the FOG data, it turned out that the headings from the Ashtech 3D-GPS were even better. This was probably due to the implementation of a new Ashtech firmware package, which allowed us to almost continuously receive reliable attitude parameters (heading, pitch and roll angles) with only occasional gaps of a few seconds. In the OS dataset FOG and Ashtech headings were available on a ping-to-ping basis. The NB-ADCP got the FOG data on single-ping resolution and, in addition, the mean difference between Ashtech and FOG headings was stored in the user buffer along with the ensembleaveraged currents.

Ship positioning was provided by conventional GPS and appeared very smooth with "selected availability" (SA) not operational. The cruising speed of the $\mathrm{R} / \mathrm{V}$ Meteor is between 10 and $11 \mathrm{kt}$ but may be significantly reduced when steaming against wind and waves. On station, the ship's velocity, similar to R/V Sonne, varies in the range from 0 to $2 \mathrm{kt}$ depending on the local wind and current speeds.

The $75-\mathrm{kHz}$ OS (firmware number 14.14) collected single-ping data using a 16-m vertical resolution with the first reliable depth cell from 24 to $40 \mathrm{~m}$ below the ship (8-m blanking range and first depth cell omitted). The first depth cell appeared to be contaminated in almost all of the profiles; it might be speculated that the potential flow around the ship's hull is responsible for this behavior; both R/V Sonne and R/V Meteor are rather large vessels. The ping interval during the R/V Meteor cruises was set to $2 \mathrm{~s}$, which forced the OS to ping as fast as possible leading to an effective time between pings of about $2.2 \mathrm{~s}$. The ping-to-ping interval is the major difference to the OS setup used during SO151, where the time between pings was set to $4 \mathrm{~s}$. The processing mode was set to low resolution (long range).

The data of the 150-kHz VMADCP (firmware number 17.10) were collected using an 8-m bin (cell) length. Usually the ADCP sends acoustic pulses for a duration that corresponds to the time it takes for the sound to travel one bin length. However, the ADCP setup allows for choosing an acoustic pulse length that is different than the bin length. Previous parameter tests had shown that the range gain achieved by using longer pulses (16 $\mathrm{m}$ ) is about $15 \%$ larger than with only $8-\mathrm{m}$ pulses. Further aquisition parameters were an ensemble interval of 5 min, averaging about 250 individual profiles, and a blanking distance of $8 \mathrm{~m}$. The FOG heading (analog output) was used as the initial heading input to the ADCP VMDAS processing. The raw data navigation information originating from the ship's GPS receiver 
was stored, and additionally the mean difference (for 5min intervals) between the FOG and Ashtech headings was written into the user buffer of the ADCP raw data files. This heading difference is used to correct individual 5-min ensembles for unreasonable fluctuations in the FOG heading; thus, we basically use the Ashtech heading. Later, on the second part of the Meteor cruise, the FOG was rebooted and a speed correction was included in the setup, thereby eliminating the large temporal deviations of the FOG heading relative to the Ashtech heading. Time was also supplied by the GPS for synchronizing the PC clock with satellite time. For postprocessing and calibration, the CODAS software package (E. Firing 1995, personal communication) was used.

\section{c. Data storage and postprocessing}

The shipboard ADCP data (OS and VMADCP) had to be calibrated for possible misalignments between the ADCP axis (usually the line between acoustic beams 3 and 4) and the ship's axis (which of course is aligned with the ship's compass). This misalignment has two sources: a mechanical source arising from the mounting of the transducer heads relative to the ship's axis, and an unknown offset in the compass synchronization with the ADCP deck units (for synchrocompasses used during SO151 only). For calibration the usual acceleration/ deceleration procedure for watertrack determination of misalignment angles was used. The assumption is that within a small region and a short time interval the currents are constant and any changes in absolute currents arise from nonperfect elimination of the ship's speed over ground. This error is large at fast ship speeds and small during station work. Thus, the aim of the calibration is to determine a misalignment angle for which the differences between on-station and underway measurements close to the station location are smallest in a least squares sense for all calibration points. Basically, this gives two independent calibration points per station: one when approaching the station and a second after the station has been completed. Approximately 150 independent estimates contributed to the calibration of the SO151 data; about 100 calibration points were used for M50/1 and 60 points for M50/2.

The quality of the calibration was checked for the Meteor cruises, where independent calibrations were calculated for both legs (the OS remained in place during the port stop between the two cruises). The resulting misalignment angles differed by $0.07^{\circ}$ with a standard deviation for the individual calibrations around $0.5^{\circ}$. Estimating the uncertainties of the mean calibration angles yields $0.05^{\circ}$ for $\mathrm{M} 50 / 1$ and $0.06^{\circ}$ for M50/2. The uncertainties of the misalignement angles were determined as the standard deviation $\left(0.5^{\circ}\right)$ divided by the square root of the number of independent contributions. As a result, the misalignment angles were the same even within these narrow margins and no significant timedependent error was found. A similar quality of the calibration was achieved for SO151 with some degradation due to the fact that the instrument had to be restarted after a power failure on board the R/V Sonne. This led to a change of the misalignment angle during the cruise, and a separate processing of the split datasets was necessary. The resulting misalignment angles were estimated to be accurate within $0.1^{\circ}$. However, velocity errors arising from small errors in the calibration do not significantly affect station data, and this is what we used from the Sonne data for comparison with LADCP data.

For the NB-ADCP during the two legs M50/1 and M50/2 the calibration quality of the misalignment angle appeared to be of similar quality for both legs; the corresponding standard deviation of the individual estimates of the misalignment angle was about $0.5^{\circ}$, or $0.05^{\circ}$ for the standard error of the mean misalignment angle, which is very similar to what was achieved for the OS data.

\section{Data overview and evaluation}

\section{a. Ship track with data coverage}

The data coverage and the ship's track during the R/V Sonne cruise SO151 are shown in Fig. 1. The focus of this cruise was on the boundary current system along the Brazilian coast. The most prominent surface current observed during this cruise is the North Brazil Current (NBC; the western boundary current) and its retroflection into the North Equatorial Countercurrent (NECC) flowing eastward at about $5^{\circ} \mathrm{N}$ during this season (Fig. 1). High vertical shears are observed in all of these currents with a maximum at the NECC, where the current decreases from almost 2 to $0 \mathrm{~m} \mathrm{~s}^{-1}$ within the upper 200-m depth (Brandt et al. 2002).

The objective of the two R/V Meteor cruises (Fig. 2) was to measure the current system along the western boundary of the subpolar North Atlantic, where the cold water from the Labrador Sea flows southward along the shelf break of Labrador toward the Grand Banks and onward to the subtropics. Compensating warm water flow is provided by the North Atlantic Current (NAC), which shows significant vertical shear, while the cold water regime in the Labrador Sea is very barotropic and of smaller horizontal scales (Fig. 2). This difference in horizontal scales is apparent in the first mode baroclinic Rossby radii, which is around $10 \mathrm{~km}$ in the Labrador Sea and about $30 \mathrm{~km}$ in the NAC regime, as calculated from CTD profiles during the M50 cruises.

\section{b. LADCP accuracy evaluation from earlier measurements}

For the LADCP data processing and accuracy considerations Fischer and Visbeck (1993) estimated the accuracy of individual current profiles at $5 \mathrm{~cm} \mathrm{~s}^{-1}$. This had been tested on the basis of LADCP versus Pegasus profiler data with the latter being a high quality reference 
with a velocity error of the order of $1-2 \mathrm{~cm} \mathrm{~s}^{-1}$ (Send 1994).

Here, we derive a direct estimate of the LADCP performance in upper-layer measurements relative to Pegasus profiles at the same stations. The datasets used for this comparison are from earlier experiments in the Indian Ocean, where the upper-layer shear was similar to the tropical Atlantic. We thereby assume that the LADCP performance in the tropical Atlantic is similar to that of the Indian Ocean; in both regions the same LADCP was used. For 18 deep ocean profiles the comparison showed that the top-to-bottom averaged velocities were very similar, and for this ensemble of 18 pairs the rms difference of about $1 \mathrm{~cm} \mathrm{~s}^{-1}$ illustrates the high accuracy of both systems for the barotropic flow.

This is different for sublayers, where a substantial difference between the two measurements may occur. Therefore, we extended this comparison for the upper 80-500-m sublayer, where the LADCP errors are largest [at the lowest nonzero vertical wavenumbers; King et al. (2001)], but which is the relevant layer for the comparisons of LADCP and OS data. The Pegasus data were interpolated to the LADCP depth cells, and for each depth cell the difference between the two was calculated. The rms difference of all estimates, that is, for 18 profile pairs times the number of depth cells, yielded similar values for the meridional and zonal components at $6.3 \mathrm{~cm} \mathrm{~s}^{-1}$ (zonal) and $5.9 \mathrm{~cm} \mathrm{~s}^{-1}$ (meridional). With the accepted error of the Pegasus data $\left(1-2 \mathrm{~cm} \mathrm{~s}^{-1}\right.$; Send 1994) this difference is almost entirely due to errors in the LADCP, for which we therefore estimate an upperlayer accuracy of $5 \mathrm{~cm} \mathrm{~s}^{-1}$, which is much larger than the error for the vertically integrated currents $(\sim 1 \mathrm{~cm}$ $\left.\mathrm{s}^{-1}\right)$.

\section{c. Comparison of OS with LADCP data}

The same LADCP (150-kHz NB) was lowered with the CTD at each station during the cruises. Regionally, from the Tropics to the subpolar region there were large differences in the magnetic deviations that had to be taken into account in the LADCP data but not in the ocean surveyor data.

Given the LADCP error estimate (see above) we now perform the OS versus LADCP comparison in the tropical Atlantic and the subpolar North Atlantic. For each of the CTD-LADCP stations we extracted the calibrated OS current profiles for comparison with the LADCP data. The OS data were averaged to 10-min ensembles, such that for each deep station of about 2-3 h duration we have 12-18 OS profiles for a statistical comparison. One such example (Fig. 3) is shown for the tropical Atlantic, with the North Brazil Current flowing northward being the prominent signal in this profile (station 52 at $\left.5^{\circ} 35^{\prime} \mathrm{S}, 34^{\circ} 41^{\prime} \mathrm{W}\right)$. The North Brazil Current clearly shows the structure of an undercurrent as described in Stramma et al. (1995). Individual current profiles (10min ensembles) scatter around most of the LADCP pro-
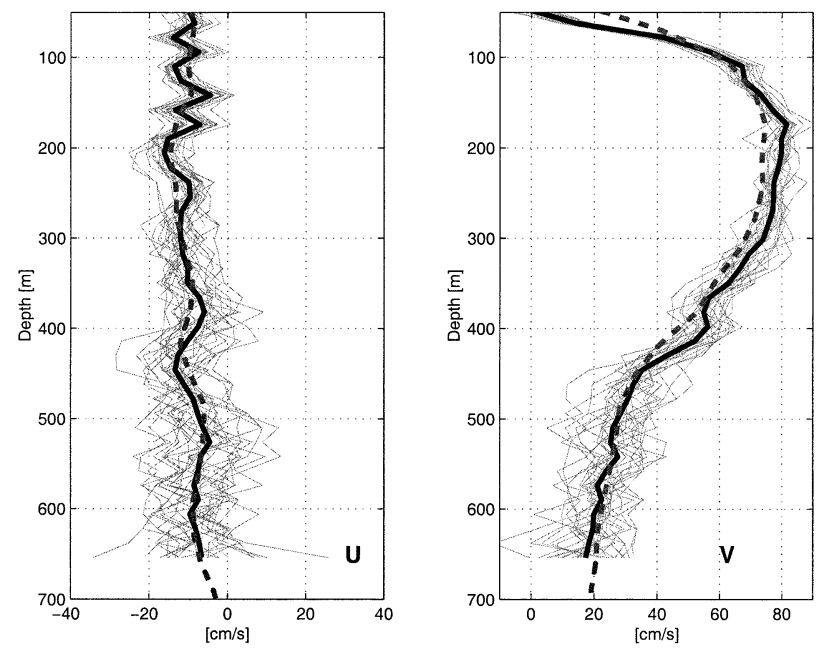

FIG. 3. Comparison of OS and LADCP data at a NBC station during the R/V Sonne cruise SO151. Individual 10-min ensemble averages of the OS data are shown as thin gray lines. Station-mean profile of the OS data is shown as heavy solid line, and for comparison the LADCP profile is shown as the heavy dashed line.

file, with the mean OS profile being very similar to that of the LADCP. However, somewhat larger vertical variability is still present in the averaged OS profile (averaging interval corresponds to station duration). This high vertical wavenumber variability is seen in most of the profiles in the NBC, occurring at different depth and with different amplitudes. Offshore, where the currents are much weaker, this variability is also much weaker. This signal is also visible in raw LADCP data but is suppressed in the final LADCP profiles by the filters that are part of the LADCP processing and that have a vertical scale of nearly $100 \mathrm{~m}$. So we conclude that the vertical structure observed by the OS is real and not a result of OS signal processing or other instrumental sources.

However, the overall correspondence between the two profiles is quite good, and the number of pings performed by the LADCP while in the upper $600 \mathrm{~m}$ is comparable to the number of pings of the OS over the whole duration of the station. This is the main reason why we did not compare shear profiles of the periods during which the LADCP was in the range of the OS, simply because in this case the number of pings of the OS are much smaller than that of the LADCP.

To put this comparison into a quantitative perspective the following procedure was applied to all station data during the two cruises. First, the station-mean OS velocities were interpolated to the same vertical grid (depth cells) of the LADCP data (10-m depth cells). Then, the differences between LADCP and OS velocities were calculated for each depth cell and all stations of the respective cruise; rms differences were calculated from these. Individual currents (for each depth cell) are shown in the scatter diagrams of Fig. 4 together with 

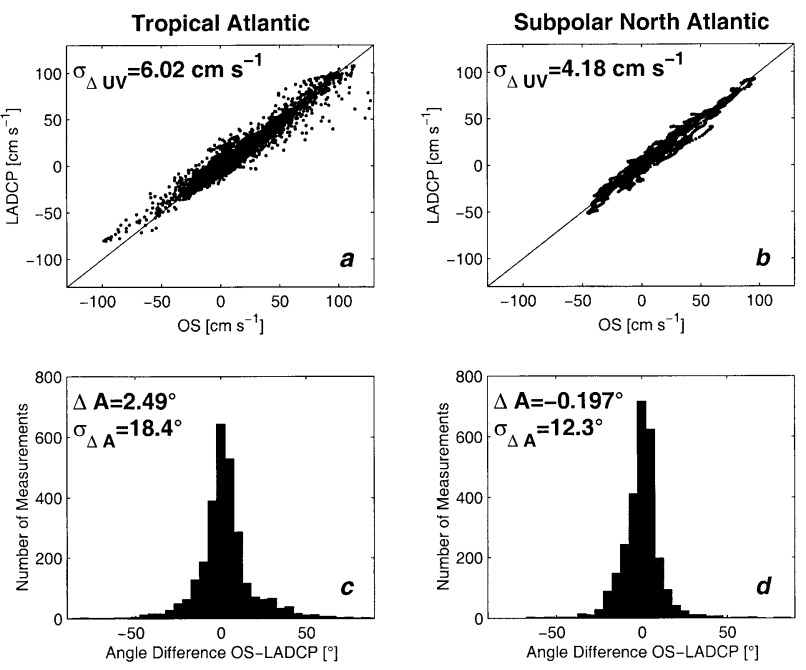

FIG. 4. Statistical comparison of OS and LADCP velocities in 10$\mathrm{m}$ depth cells between 80 and $500 \mathrm{~m}$ : (a), (c) for the tropical Atlantic (SO151), and (b), (d) for the subpolar North Atlantic (M50); (a), (b) scatter diagrams of the combined zonal and meridional current components; (c), (d) histograms of the differences in flow direction for currents larger than $10 \mathrm{~cm} \mathrm{~s}^{-1}$.

their rms values; for this purpose the $U$ (zonal) and $V$ (meridional) components are combined.

In the tropical Atlantic we had 76 profile pairs for comparison and the rms difference between the OS and LADCP data in the depth range 80-600 m was about $6 \mathrm{~cm} \mathrm{~s}^{-1}$, very similar to what has been achieved in the Pegasus versus LADCP comparison in a similar highshear environment. For the subpolar region the rms difference between OS and LADCP based on 77 profile pairs is much smaller, at $4 \mathrm{~cm} \mathrm{~s}^{-1}$. This result is somewhat surprising and is thought to be the result of the small-scale vertical shears that are larger in the tropical Atlantic profiles than in the subpolar region. It is rather unlikely that the navigation data are responsible for this behavior, as its impact is less than $0.5 \mathrm{~cm} \mathrm{~s}^{-1}$ for onstation data. In contrast, the filters in the LADCP processing have a larger effect on the sheared tropical profiles compared to the smoother profiles in the subpolar regime. This is also reflected in the appearance of the scatter diagrams for the two regions. In the Tropics the differences between the measurements scatter randomly around the reference line (Fig. 4a). This is different in the subpolar region where the scatter diagrams exhibit the profiles, a result of the barotropic nature of the flow in the subpolar region (Fig. 4b). The interpretation of the result shown here is that in both regions the OS provided very accurate on-station measurements, and if we assume that the rms difference is prodominantly due to the LADCP (see LADCP-Pegasus comparison), then the OS on-station accuracy should be of the order of 1 $\mathrm{cm} \mathrm{s}^{-1}$.

In addition to the current differences we also determine mean orientation differences of the currents (Figs. $4 \mathrm{c}, \mathrm{d})$. These differences are calculated only for currents

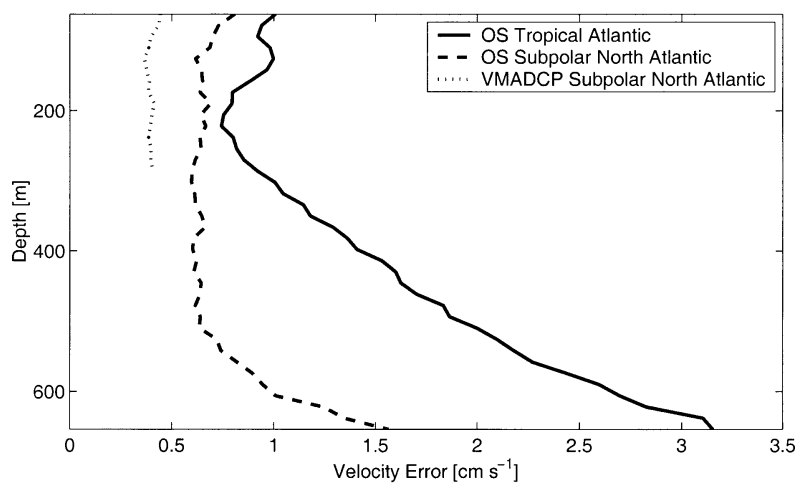

FIG. 5. Velocity error of the $75-\mathrm{kHz}$ OS for on-station data of 1$\mathrm{h}$ duration during SO151 (solid line) and for the combined M50 cruises (dashed line), and similarly of the 150-kHz VMADCP used in parallel during the M50 cruises (dotted line). Note the shorter depth range of the NB-ADCP.

larger than $10 \mathrm{~cm} \mathrm{~s}^{-1}$ in the layer of interest. Although the scatter appears relatively large, the mean difference is near zero, and thus there is no bias in the current directions. The direction scatter is somewhat larger in the Tropics, and so is the mean direction difference, a result that comes from the larger shear and the uncertainty in the LADCP depth record (of the order of 10 $\mathrm{m}$ close to the surface). A small difference in the depth determination of the LADCP data calculated by integration of the vertical velocity measurements would explain a direction deviation of this magnitude.

Another obvious signal seen in the individual station data (Fig. 3) is the increase in the velocity scatter with distance from the OS transducer. This will also be quantified on the basis of all available stations. For a quick estimate we use the ping-to-ping accuracy $\left(17 \mathrm{~cm} \mathrm{~s}^{-1}\right)$ given in Table 1. Although the typical station duration is $2-3 \mathrm{~h}$, we performed the error calculation for just 1$\mathrm{h}$ segments during the stations in order to have the same interval length on each station, including the shallower ones. Thus, for the tropical Atlantic measurements about 900 individual pings (one ping every $4 \mathrm{~s}$ ) contribute to each error profile. Given the theoretical ping-to-ping accuracy of $17 \mathrm{~cm} \mathrm{~s}^{-1}$ and dividing this number by the square root of the number of contributing pings, we have an expectation for the accuracy achievable by the OS measurements $\left(0.6 \mathrm{~cm} \mathrm{~s}^{-1}\right)$. For comparison we calculated the ensemble mean and the standard deviation for each depth cell, and from the standard deviation the standard error of the mean is then derived as standard deviation divided by the square root of the number of contributing pings. As a result we had a profile of the standard error at each station, and by averaging these for the number of stations available we derived the error profiles shown in Fig. 5 for the OS in the two regions and the VMADCP for comparison in the subpolar region.

The expected error is somewhat lower than what has been calculated from the observed scatter of the flow 
(Fig. 5) in the upper $300 \mathrm{~m}$ (or the layer within $300 \mathrm{~m}$ from the transducer), and the larger error might be attributed to both higher acoustic noise and additional scatter introduced by oceanic variability, for example, by internal waves. Below about $300 \mathrm{~m}$ the error increases almost linearly with distance from the transducer and reaches about $2.5 \mathrm{~cm} \mathrm{~s}^{-1}$ at a distance of $600 \mathrm{~m}$. However, a $20 \%$ reduction of reliable data (percentage of good measurements) in the 300-500-m depth layer (as will be shown later) could not explain the magnitude of the error increase with depth by just a reduction in the number of reliable pings. Environmental conditions such as high vertical shear layers in the equatorial Atlantic and the internal wave field might cause additional scatter, but it is not clear why this should generate the observed linear increase with depth.

For the subpolar North Atlantic one would expect smaller scatter, as the number of pings contributing to $1 \mathrm{~h}$ of data was almost twice as large (one ping every $2.2 \mathrm{~s}$ ). The effect of the larger number of contributions is reflected in the error curve for the Meteor cruise, but again the observed $0.6 \mathrm{~cm} \mathrm{~s}^{-1}$ are larger than what is expected from instrumental noise alone $\left(0.4 \mathrm{~cm} \mathrm{~s}^{-1}\right)$. In this case the estimated observational error is nearly constant in the upper $500 \mathrm{~m}$. Below that depth the error increases to about $1.5 \mathrm{~cm} \mathrm{~s}^{-1}$ at the range limit of $650 \mathrm{~m}$.

By comparing the two regimes (Tropics and subpolar) it is more likely that the larger error in the deeper layers is due to a depletion of scatterers at depth and an associated lower signal-to-noise ratio. This depletion at depth is larger in the Tropics and we believe that the error increase in the Tropics is caused by larger than expected errors at low signal-to-noise ratios.

The same calculation was performed for the data from the conventional $150-\mathrm{kHz}$ NB-ADCP that was used in parallel (M50 only) but limited in range to the upper 50-300-m depth layer. Within this layer the error profiles for 1-h on-station averages were a little less than $0.5 \mathrm{~cm} \mathrm{~s}^{-1}$, and thereby even smaller for the OS data in the same area. The reduced scatter in the VMADCP data has two main reasons: first, the number of contributions within $1 \mathrm{~h}$ of data is about twice the number for the OS; second, the higher frequency results in an accuracy gain of a factor of 2 that is larger than the loss of accuracy by the smaller 8-m bin length (square root of 2 reduction). The predicted VMADCP error for a 1-h interval and the chosen parameters is approximately 0.3 $\mathrm{cm} \mathrm{s}^{-1}$ and thereby also a little less than the observed errors.

Summarizing, the on-station variability results in errors of the order of $1 \mathrm{~cm} \mathrm{~s}^{-1}$ for both instruments. At greater depth the error of the OS increases significantly, especially in the tropical regime. This is thought to be the combined result of a reduced number of scatterers and their depth distribution.

\section{d. Comparison of underway VMADCP and OS data}

The quality of underway current measurements is much more difficult to evaluate. Much depends on the
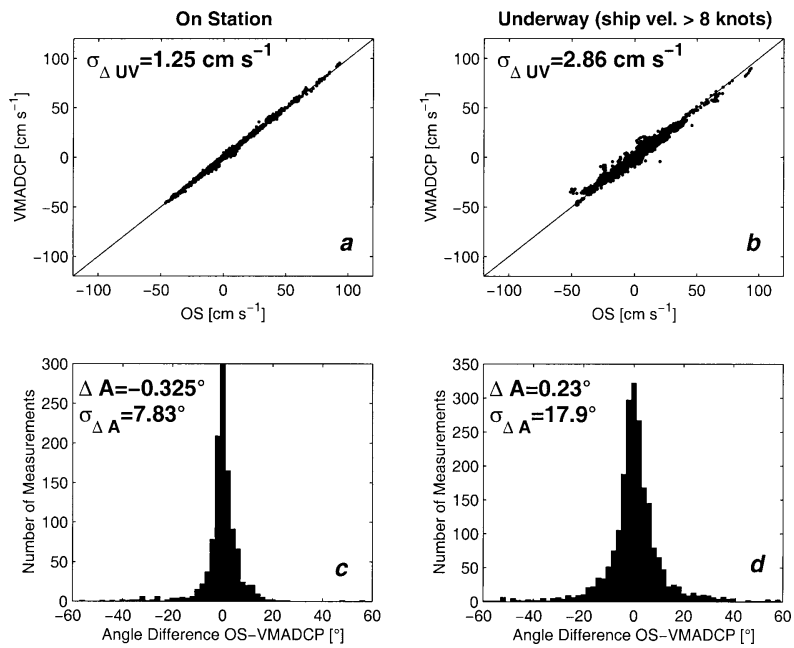

FIG. 6. Statistical comparison of OS and VMADCP velocities in 16-m depth cells between 50 and $300 \mathrm{~m}$ : (a), (c) on-station data (M50), and (b), (d) for underway measurements during M50; (a), (b) scatter diagrams of the combined zonal and meridional current components; (c), (d) show histograms of the differences in flow direction.

quality of the calibration of heading misalignments and on the quality of the navigation sources. As no high quality reference is available the evaluation is based on internal consistency checks and a comparison with a standard $150-\mathrm{kHz}$ NB-ADCP that was run in parallel.

Before comparing underway measurements we evaluated the on-station data. Similar to the OS versus LADCP on-station comparison we made a statistical comparison of the OS station data with the simultaneous VMADCP data in the depth range from 50 to $300 \mathrm{~m}$ (Fig. 6). To obtain identical vertical resolution the VMADCP data were interpolated onto the OS vertical grid (16-m depth cells). Based on 89 stations during the Meteor cruises M50/1 and M50/2, the difference between the two measurements shows a negligible mean difference of the order of $0.1 \mathrm{~cm} \mathrm{~s}^{-1}$; similar results are obtained for underway data discussed below. Thus, for transport estimates in the upper $300 \mathrm{~m}$ and for a 1000$\mathrm{km}$-long transect, typical for a cruise leg like the Meteor cruises, one would expect a transport difference of only $0.3 \mathrm{~Sv}\left(1 \mathrm{~Sv}=10^{6} \mathrm{~m}^{3} \mathrm{~s}^{-1}\right)$. The rms difference between the two measurements is $1.25 \mathrm{~cm} \mathrm{~s}^{-1}$ for on-station data (Fig. 6). If we assume the errors of the two systems to be comparable, that is, both instruments contribute about the same amount of scatter, then the on-station error of each instrument should be a little less than $1 \mathrm{~cm} \mathrm{~s}^{-1}$, similar to what was estimated for the OS when compared to the LADCP data. The current directions were the same within the error bounds with little scatter around $0^{\circ}$.

For underway measurements, that is, for ship speeds larger than $8 \mathrm{kt}$, the rms difference between the two data sources increased to about $3 \mathrm{~cm} \mathrm{~s}^{-1}$ (Fig. 6). If again assuming a similar error in both instruments, this yields $2 \mathrm{~cm} \mathrm{~s}^{-1}$ accuracy for each of them. Again, the mean 

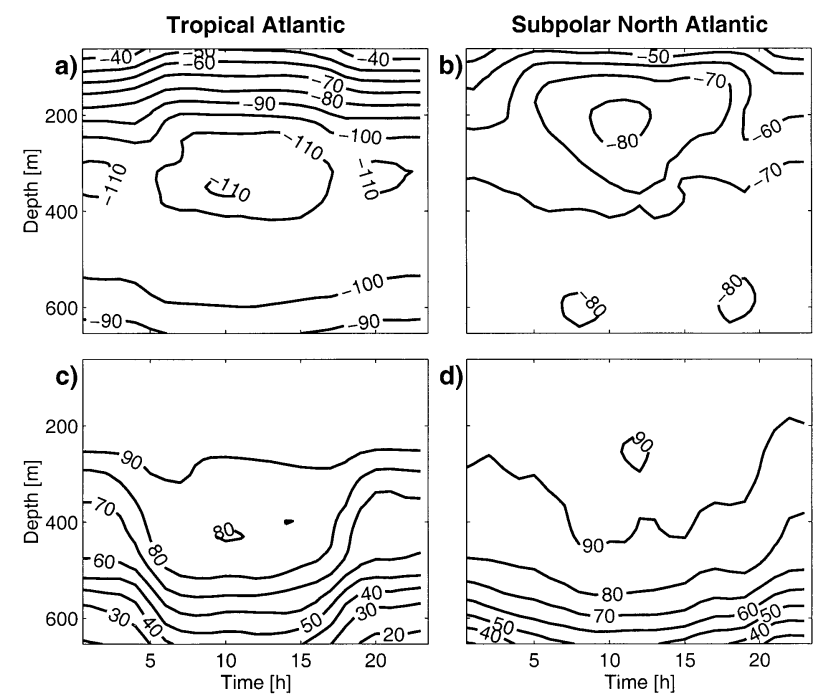

FIG. 7. Mean daily cycle of relative target strength (a), (b) and percentage of reliable measurements (c), (d) for the tropical Atlantic (a), (c) and the subpolar North Atlantic (b), (d).

difference of current directions is close to zero, but the scatter increased by a little more than a factor of 2 . However, the overall accuracy of both datasets is quite high and is attributed to a combination of the quality of the acoustic measurements, of the navigation data including the Ashtech headings that were much improved compared to previous experiments, and finally to the quality of the calibration of the two transducer misalignement angles.

\section{e. Measurement range}

The range of reliable measurements showed considerable variability caused by two different environmental conditions. The first is due to the amount of scatterers in the water column that might either be different due to regional differences in plankton abundance or in their ability to migrate vertically during the course of the day. This is shown for the tropical Atlantic and the subpolar region (Fig. 7). In both areas upward plankton migration during the night led to a depletion of scatterers in the deeper layers and, consequently, we observed a significant nighttime reduction in the measurement range of the OS in both regimes. For each of the cruises a mean daily cycle has been calculated for the relative target strength and for the percentage of good data. The longitudinal daytime dependence ( $1 \mathrm{~h}$ per $15^{\circ}$ longitude) has been taken into account in this calculation. In the absence of an absolute reference, the target strength is calculated relative to the surface backscatter, which is set to $-40 \mathrm{~dB}$ for both regions. In the tropical area (Fig. 7a) we observed a strong vertical decline of the backscattered energy in the upper $200 \mathrm{~m}$. At that depth the target strength is some $50 \mathrm{~dB}$ lower than near the surface, while in the subpolar North Atlantic (Fig. 7b) it
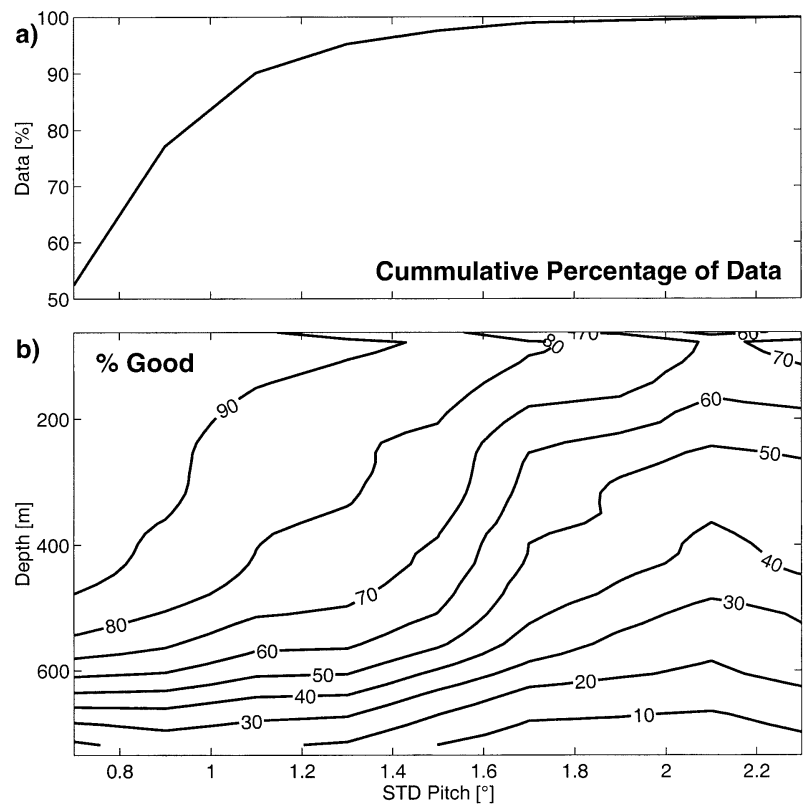

FIG. 8. (a) The cumulative amount of data for certain pitch ranges. (b) OS measurement range identified by the percent-good parameter versus the std dev of the pitch angle during M50.

is only about $30 \mathrm{~dB}$ lower than in the near-surface layer. However, both regions show an intermediate minimum target strength centered around noon, while at larger depths we observed backscatter minima during the night. This is much more pronounced in the Tropics than in the subpolar region. Consequently, the range of reliable data varies much more in the Tropics (Fig. 7c), with the 50\%-good isoline (taken as the discriminator for reliable and less reliable data) ranging from $500 \mathrm{~m}$ at night to more than $600 \mathrm{~m}$ at noon. Generally, the same isoline is about $20 \%$ deeper in the subpolar regime (near $600 \mathrm{~m}$ at night and more than $650 \mathrm{~m}$ around noon). Thus, the measurement range in the subpolar North Atlantic is about $20 \%$ larger than in the tropical Atlantic, and this is due to the abundance of scatterers and their migration pattern.

The second range-limiting factor is due to the behavior of the ship during heavy wind conditions and the ship's heading relative to the wind direction. This could be most easily evaluated by the pitch and roll angles supplied by the Ashtech 3D-GPS receiver (Fig. 8). The standard deviation of the pitch angle was calculated for pitch values measured at each individual ping during the 10-min averaging intervals. Shown (Fig. 8a) is the cumulative percentage of data below a certain pitch variability; for example, about $80 \%$ of the data during the cruise had pitch angle standard deviations smaller than $1^{\circ}$.

For the R/V Meteor dataset a strong dependency of measurement range was detected as the ship encountered a heavy storm with wind speeds above $25 \mathrm{~m} \mathrm{~s}^{-1}$. This almost led to a total loss of reliable OS data when $\mathrm{Me}$ teor headed against swell and wind waves. Both ADCPs 
TABLE 2. Ocean Surveyor performance for 1-h ensembles.

\begin{tabular}{lcccc}
\hline \hline \multicolumn{1}{c}{ Region and ship's speed } & $\begin{array}{c}\text { Cell size } \\
(\mathrm{m})\end{array}$ & $\begin{array}{c}\text { Range } \\
(\mathrm{m})\end{array}$ & $\begin{array}{c}\text { Accuracy } \\
\left(\mathrm{cm} \mathrm{s}^{-1}\right)\end{array}$ & Conditions \\
\hline Tropics, on station, upper 300 m & 16 & $500-600$ & $\sim 1$ & Calm \\
Tropics, on station, 300-600 m & 16 & $500-600$ & $\sim 2$ & Calm \\
Tropics, underway, 0-600 m & 16 & $500-600$ & $\sim 3$ & Calm \\
Subpolar, on station, upper 300 m & 16 & $>600$ & $\sim 1$ & Moderate sea state \\
Subpolar, on station, 300-600 m & 16 & $>600$ & $\sim 1$ & Moderate sea state \\
Subpolar, underway, upper 300 m & 16 & $>600$ & $\sim 2$ & Moderate sea state \\
Subpolar, underway, 300-600 m & 16 & $>600$ & $\sim 4$ & Moderate sea state \\
Subpolar, underway, upper 300 m & 16 & $\leq 300$ & Rough sea \\
\hline
\end{tabular}

(the VMADCP and the OS) were affected, with the relative range reduction somewhat different. But the ADCPs were also mounted at different places at the ship's hull, also with respect to acoustic disturbances (e.g., air bubbles).

During the stormy periods the pitch angle variability increased considerably and the isoline of 50\%-good data (Fig. 8b) rose from more than 600-m depth to less than $300-\mathrm{m}$ depth, a range decrease by a factor of 2 . However, this range decrease is not linear but shows a steplike structure occurring where the standard deviation of the pitch angles is about $1.5^{\circ}$. During M50 about $4 \%$ of the data were aquired during periods in which the pitch standard deviation was larger than $1.5^{\circ}$, corresponding to about $1 \frac{1}{2}$ days of stormy weather during which the $\mathrm{R} / \mathrm{V}$ Meteor was steaming against heavy seas.

\section{Discussion and conclusions}

The ocean surveyor was used in an operational mode to measure upper ocean currents in the tropical and subpolar North Atlantic. The instrument setup was chosen as a compromise between range, accuracy, and vertical resolution, the parameters being narrowband processing, 16-m resolution, and single-ping sampling with a ping interval of 2-4 s. Data postprocessing included a calibration of the OS data for heading misalignments and subsequent ensemble averaging. A detailed comparison with independent on-station data acquired by LADCP and with underway measurements of a conventional NB-ADCP revealed rather high accuracy of this new tool. Measurement ranges varied from 500 to $700 \mathrm{~m}$ depending on the vertical distribution of scatterers and were associated with both regional and temporal abundance of scattering particles. Under rough weather conditions we observed a significant reduction of the measurement range, presumably caused by air bubbles in front of the transducer head when the ship was heading against heavy swell and wind sea.

A rather surprising detail was that in no case did we observe any cross talk between the different ADCPs used. Even when the OS and an NB-ADCP where pinging "cheek to cheek" no disturbances were recognized in either of the instruments, although frequencies were multiples of each other at 150 and $75 \mathrm{kHz}$, respectively.

Summarizing, the ocean surveyor is a reliable device for operationally measuring upper ocean currents in a wide range of environmental conditions (Table 2). Although there were no direct comparisons possible for the underway data in the Tropics or for the underway data below 300-m depth in the subpolar region, we included a crude estimate of the OS accuracy for these two cases. The estimates are based on the number of accepted measurements (percent-good parameter, e.g., Fig. 8) and should be interpreted as guidelines rather than hard numbers. The rationale for the listed error magnitudes for deep underway data is that on-stations we observed an error increase with depth (about a factor of 2 compared to the upper-layer errors) and we believe that this should also be valid for underway data.

Technically, the OS is easy to handle and the transducer head requires much less space than a traditional ADCP of the same frequency. To exploit the full capability of the OS, data should be sampled at singleping resolution, which makes postprocessing more flexible, but requires large storage capacity (about $1 \mathrm{~GB}$ per week of operation) and quite powerful personal computers are needed to keep the postprocessing time in an adequate range. Additional and more systematic tests of the achievable ranges and accuracies at different parameter settings, for example, vertical resolution, should be performed in the future.

Compared to older vessel-mounted ADCP systems we found measurement ranges of the OS similar to those of a $75-\mathrm{kHz}$ NB-ADCP system (no longer available); this statement is based on our own experiences with $\mathrm{R} / \mathrm{V}$ Meteor's former $75-\mathrm{kHz}$ NB-ADCP used in the same areas. Other types of ADCPs used in shipboard applications are BB-ADCPs of similar frequencies. BBADCP ranges are sufficiently smaller than those of NBADCPs; at least this was the case for moored self-contained $(150 \mathrm{kHz})$ versions of these instruments, which were deployed in the Labrador Sea. As we have used the OS only in its narrow bandwidth mode we assume the OS depth ranges are also sufficiently larger than those of comparable BB-ADCPs.

In terms of future perspectives we think that besides a general improvement of measuring the near-surface flow at least two applications will benefit from the relatively large range and the accuracy of the OS measurements. First, attempts to use direct current obser- 
vations for combining hydrographic observations and upper ocean currents (e.g., Saunders 1992) will benefit mainly from the extended vertical range, allowing for reference layers applied to geostrophic currents well below the near-surface Ekman regime. Second, it has been shown that low-mode baroclinic errors in LADCP profiles can be reduced by including absolute currents near the bottom (Visbeck 2002). It is expected that a similar inclusion of high quality near-surface currents over a sufficient depth range will lead to further error reduction in full ocean depth current profiles from LADCPs.

Acknowledgments. We would like to thank Fran Rowe and RD Instruments who generously provided the instrument for the R/V Sonne cruise, the captain and crew of the R/V Sonne and the R/V Meteor, and the Chief Scientists L. Stramma and F. Schott. We would further like to thank E. Firing who kindly made available his software for reading raw OS data, and F. Schott for many helpful comments and suggestions.

\section{REFERENCES}

Brandt, P., A. Rubino, and J. Fischer, 2002: Large-amplitude internal solitary waves in the North Equatorial Countercurrent. J. Phys. Oceanogr., 32, 1567-1573.
Firing, E., T. K. Chereskin, and J. A. Gast, 1989: On identifing and screening filter skew and noise bias in acoustic Doppler current profiler measurements. J. Atmos. Oceanic Technol., 6, 10401054.

Fischer, J., and M. Visbeck, 1993: Deep velocity profiling with selfcontained ADCPs. J. Atmos. Oceanic Technol., 10, 764-773.

—- F. Schott, and L. Stramma, 1996: Currents and transports of the Great Whirl-Socotra Gyre system during the summer monsoon, August 1993. J. Geophys. Res., 101, 3573-3587.

Joyce, T. M., T. S. Bittermann, and K. E. Prada, 1982: Shipboard acoustic profiling of upper ocean currents. Deep-Sea Res., 29, 903-913.

King, B. A., E. Firing, and T. M. Joyce, 2001: Shipboard observations during WOCE. Ocean Circulation and Climate, G. Siedler et al., Eds., Academic Press, 99-122.

Saunders, P. M., 1992: Combining hydrographic and shipborn ADCP measurements. Deep-Sea Res., 39, 1417-1427.

Schott, F., M. Visbeck, and J. Fischer, 1993: Observations of vertical currents and convection in the central Greenland Sea during the winter of 1988-1989. J. Geophys. Res., 98, 14 401-14 421.

$\ldots, \ldots, \ldots$, L. Stramma, and Y. Desaubies, 1996: Observations of deep convection in the Gulf of Lions, northern Mediterranean, during the winter of 1991/92. J. Phys. Oceanogr., 26, 505-524.

Send, U., 1994: The accuracy of current profile measurements: Effect of tropical and midlatitude internal waves. J. Geophys. Res., 99, $16229-16236$.

Stramma, L., J. Fischer, and J. Reppin, 1995: The North Brazil Undercurrent. Deep-Sea Res., 42, 773-795.

Visbeck, M., 2002: Deep velocity profiling using lowered acoustic Doppler current profilers: Bottom track and inverse solutions. $J$. Atmos. Oceanic Technol., 19, 794-807. 2001. 